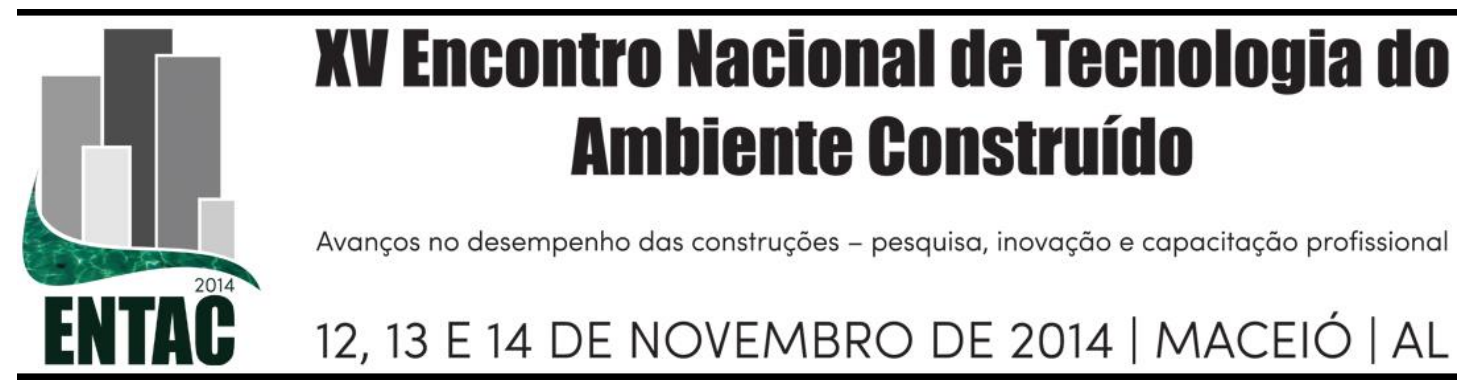

\title{
ACESSIBILIDADE ESPACIAL PARA IDOSOS: ESTUDO DE UM APARTAMENTO DE PADRÃO ELEVADO EM MACEIÓ/AL
}

\author{
MONTENEGRO, Fabíola de C.; TOLEDO, Alexandre
}

(1) UFAL, (82) 96396138, e-mail: fabiolacmontenegro@gmail.com (2) UFAL, e-mail: prof.amtoledo@gmail.com

\begin{abstract}
RESUMO
Esse artigo avalia os parâmetros de acessibilidade espacial para idosos em um apartamento de padrão elevado ofertado pelo mercado imobiliário de Maceió/AL com apelo publicitário de adequação de seus espaços a esse perfil de usuário. Como uma pesquisa de caráter exploratório, esse estudo de caso apresenta os resultados parciais do trabalho final de mestrado. Para a avaliação, aplicou-se o "laudo de avaliação da acessibilidade espacial" que faz parte do método de Avaliação de Projeto Habitacional proposto por Gabriela Pereira. A maioria das incompatibilidades entre os espaços e o usuário idoso evidencia que houve um subdimensionamento dos ambientes do apartamento em relação aos móveis e equipamentos propostos, assim como, uma má distribuição do leiaute dos ambientes, muitas vezes, ocasionada pela proposição de uma quantidade de móveis e/ou equipamentos superior ao que o ambiente poderia acomodar. Além disso, a não disponibilização de projetos complementares e do memorial descritivo do apartamento objeto desse estudo prejudicou parte das avaliações realizadas. Espera-se que pesquisas como esta possam subsidiar futuros projetos na área e facilitar a aplicação dos parâmetros de acessibilidade espacial.
\end{abstract}

Palavras-chave: Acessibilidade espacial, Idosos, Apartamento de padrão elevado.

\begin{abstract}
This article evaluates the parameters of spatial accessibility for the elderly in a high standard apartment offered by the housing market in Maceio/AL with publicity appeal of that its spaces are appropriate to this user profile. As an exploratory research, this case study presents the partial results of the master's dissertation. For the evaluation, we applied the "evaluation report of spatial accessibility" which is part of the method of Assessment of Housing Project proposed by Gabriela Pereira. Most incompatibilities found between the spaces and the needs of the elderly showed that the rooms of the apartment were undersized in relation to the furniture and to the equipment proposed and that there is an unequal distribution of layout caused by the amount of furniturelequipment suggested to this space, superior to that this ambient could accommodate. Moreover, the unavailability of additional projects and of the descriptive memorial of the apartment, object that study, damaged a part of the assessments. It is expected that such surveys can support future projects in the area and facilitate the application of the parameters of spatial accessibility.
\end{abstract}

Keywords: Spatial accessibility, Elderly, High standard apartment.

\section{INTRODUÇÃO}

O aumento do número de idosos na população brasileira - dados do último censo do IBGE (2010) registraram que o número de pessoas com idade igual ou superior a 60 anos no Brasil é de cerca de 20 milhões, $11,1 \%$ da população total - aponta para a necessidade de se projetar moradias adequadas a atender a essa nova demanda populacional por meio da proposição de espaços acessíveis, que possam proporcionar maior autonomia e independência, melhorando a qualidade de vida desses usuários. 
Segundo Bestetti (2006), uma pessoa idosa que se torne frágil ou se incapacite pode residir normalmente em uma unidade habitacional, dependendo de sua instalação. No entanto, atualmente, a maioria dos projetos arquitetônicos, inclusive os edifícios residenciais, é produzida para atender o homem ainda no início de sua vida adulta, com altura mediana e sem nenhuma limitação em suas funções (ROJAS, 2005).

No Brasil, a moradia, principalmente para as classes A e B da população, é espaço do mercado imobiliário. Em Maceió, observa-se um forte investimento do setor imobiliário na construção de edifícios residenciais multifamiliares de padrão elevado; entretanto, não se tem conhecimento se as práticas projetuais adotadas para a construção desses edifícios são, de fato, compatíveis com as necessidades do usuário idoso, considerando os parâmetros de acessibilidade espacial previstos em leis e normas específicas.

O objetivo desse artigo é avaliar os parâmetros de acessibilidade espacial para idosos em um apartamento de padrão elevado ofertado pelo mercado imobiliário de Maceió/AL com apelo publicitário de adequação de seus espaços a esse perfil de usuário. Como uma pesquisa de caráter exploratório, esse estudo de caso apresenta os resultados parciais do trabalho final de mestrado. Para a avaliação, aplicou-se o "laudo de avaliação da acessibilidade espacial" que faz parte do método de Avaliação de Projeto Habitacional proposto por Gabriela Pereira e que ratifica os resultados obtidos por meio das demais etapas de avaliação desenvolvidas para o trabalho final.

\section{FUNDAMENTAÇÃO TEÓRICA}

O conceito de acessibilidade é bastante amplo e, dependendo do enfoque e da área de conhecimento, assume diversos significados. A Associação Brasileira de Normas Técnicas (ABNT) define acessibilidade como sendo a "possibilidade e condição de alcance, percepção e entendimento para a utilização com segurança e autonomia de edificações, espaço, mobiliário, equipamento urbano e elementos" (ABNT, 2004, p.2).

Dischinger, Bins Ely e Piardi (2008), aprofundam esse conceito ao considerar a acessibilidade espacial como um critério fundamental de projetos que prevê soluções para as necessidades do usuário, relacionando-se a tudo o que diz respeito ao acesso e à interação de um indivíduo com o ambiente, e subdividindo-a em quatro componentes fundamentais - orientação, comunicação, deslocamento e uso - que devem ser atendidos em sua totalidade e, dependendo das condições dos usuários e das suas necessidades, o não cumprimento de um deles pode comprometer todos os demais.

No entanto, a garantia de acesso nem sempre foi uma preocupação do Estado Brasileiro. No Brasil, as questões relativas à acessibilidade se tornaram mais visíveis a partir da década de 1980. Surgiram novos estudos, leis, decretos e normas técnicas abordando os direitos das pessoas com deficiência e garantindo a acessibilidade ao meio físico (ORNSTEIN; ALMEIDA PRADO; LOPES, 2010).

Distante das pautas políticas, o idoso também começou a ganhar espaço nesse campo nas últimas décadas. A Política Nacional do Idoso, de 1994, e o Estatuto do Idoso, de 2003, já definem competências nas áreas de habitação, visando melhorar a qualidade de vida dessa parcela da população. A temática do envelhecimento vem despertando, também, o interesse da comunidade científica em geral e algumas pesquisas realizadas já começam a contribuir para um melhor entendimento das reais necessidades do idoso em sua habitação e a permitir a aplicação de alguns conceitos e diretrizes no projeto arquitetônico residencial (MONTENEGRO, 2013).

No que diz respeito à residência, é importante considerar que seus espaços serão utilizados por muitos anos e, em alguns casos, para o resto da vida. Por isso, é fundamental 
considerar as necessidades que as pessoas possam ter durante os vários estágios da vida, até chegar à velhice (DUARTE; COHEN, 2004).

Uma "casa" deve ser projetada de modo a prever a longevidade de seus moradores, caso contrário, com o passar dos anos, tornar-se-á hostil e, em vez de abrigo, transformar-se-á em uma armadilha que pode inviabilizar a continuidade da vida independente e autônoma dos idosos, inclusive daqueles que não apresentam qualquer tipo de deficiência (MONTENEGRO, 2013).

\section{CARACTERIZAÇÃO DO OBJETO DE ESTUDO}

O objeto deste estudo foi escolhido com base na pesquisa realizada no mercado imobiliário de Maceió, junto às corretoras e construtoras, para identificar os lançamentos de apartamentos ofertados com o apelo de adequação de seus espaços ao morador idoso.

Entre os projetos encontrados, o Edifício Maison Du Versailles, localizado na Rua Publicitário Ranildo Cavalcante, no bairro da Gruta de Lourdes, foi lançado pela construtora R Pontes como sendo "o primeiro edifício adaptado para a terceira idade em Maceió" (BARROS, 2012).

Para esse estudo, foi avaliado o apartamento com três suítes, visto que ele apresentou piores resultados no que diz respeito à acessibilidade espacial ao idoso. Essa tipologia de apartamento, correspondente às terminações 1 e 4, possui sala de estar/jantar, varanda, lavabo, cozinha, área de serviço, uma suíte de casal, duas suítes reversíveis e dependência de empregada, com área total de $122 \mathrm{~m}^{2}$ (Figura 1).

\section{Figura 1 - Planta baixa do pavimento tipo com demarcação das terminações do apartamento avaliado no Edifício Maison Du Versailles}

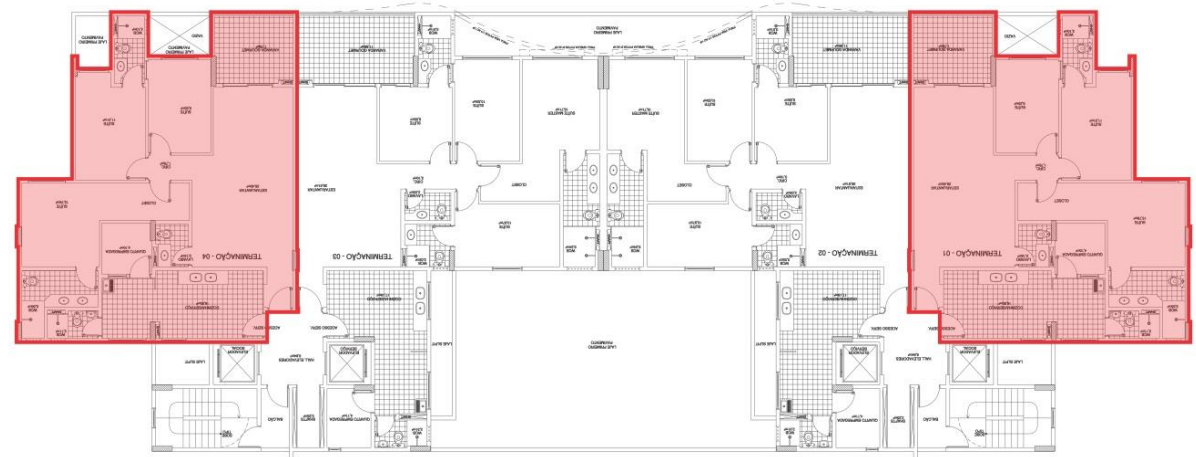

Fonte: Adaptado de Construtora R Pontes LTDA (2013)

\section{PROCEDIMENTOS METODOLÓGICOS}

Para análise da acessibilidade espacial na habitação do idoso, aplica-se o "laudo de avaliação da acessibilidade espacial" que faz parte do Método de Avaliação de Projeto Habitacional proposto por Pereira (2007). O laudo é obtido com a aplicação da planilha de avaliação, na qual se encontram elencados os principais itens a serem avaliados por meio da leitura do projeto arquitetônico, dos projetos complementares, do memorial descritivo e dos demais instrumentos que forneçam informações sobre o projeto.

Como instrumento técnico componente do Método de Avaliação de Projeto Habitacional, a planilha elaborada pela pesquisadora baseia-se na metodologia de avaliação utilizada pelo Ministério Público de Santa Catarina - MP/SC, elaborada por uma equipe 
multidisciplinar, coordenada pela Dr. ${ }^{a}$ Sonia Groisman Piardi, com a participação das professoras Vera Helena Bins Ely e Marta Dischinger do Programa de Pós-graduação em Arquitetura e Urbanismo da Universidade Federal de Santa Catarina - UFSC.

A definição do laudo sobre esse estudo, considerou o acesso por qualquer usuário idoso, com enfoque para aqueles com alguma deficiência física ou cognitiva. Para se adequar a essa pesquisa, alteraram-se alguns dos elementos da planilha de avaliação definida por Pereira (2007), pois eles não se aplicavam ao objeto do estudo. Desconsideraram-se os seguintes itens do cabeçalho: a tipologia da residência, sua localização e a condição do sítio. Excluiu-se o subgrupo "Acesso externo", por ele avaliar a área externa ao apartamento. Reordenaram-se os subgrupos inseridos nos grupos dos requisitos essenciais e complementares de acordo com as avaliações realizadas, a fim de facilitar a compreensão dos resultados obtidos.

Para a avaliação da acessibilidade espacial, dividiram-se os ambientes do apartamento em setor social, de serviço e íntimo e considerou-se o leiaute proposto pela construtora $\mathrm{R}$ Pontes, responsável pelo projeto.

\section{AVALIAÇÃO DA ACESSIBILIDADE ESPACIAL}

Com base nos projetos arquitetônico e complementares e no memorial descritivo disponíveis, aplicou-se a planilha de avaliação da acessibilidade espacial determinandose o laudo sobre o projeto, considerando-se o acesso pelo idoso, especialmente por aquele com algum tipo de deficiência.

Acesso e circulação

Equipamentos de controle de acesso

Não existe controle visual entre o interior do apartamento e a rua, pois o peitoril da varanda e das janelas - de $110 \mathrm{~cm}$ - está acima do recomendado - entre 75 e $100 \mathrm{~cm}$ do piso. Também não está prevista a instalação de nenhum equipamento que facilite a comunicação do idoso surdo e/ou mudo.

\section{Portas}

O projeto do apartamento apresenta demarcações bem definidas das áreas social, íntima e de serviço, o que facilita a leitura e a compreensão dos ambientes pelo idoso. A inexistência de desnível nas soleiras favorecem a circulação.

A maioria das portas do apartamento possui giro de $90^{\circ}$ (Figura 2), excetuando-se as portas que dão acesso à varanda, que são de correr (Figura 3). Observa-se que apenas as portas de entrada pelo setor social e pelo de serviço, com largura de $90 \mathrm{~cm}$, e as portas que dão acesso à varanda, com $95 \mathrm{~cm}$ de vão, permitem um circuito de circulação adequado ao idoso em cadeira de rodas ou com outro aparelho de auxílio à locomoção. 
Figura 2 - Portas de abrir

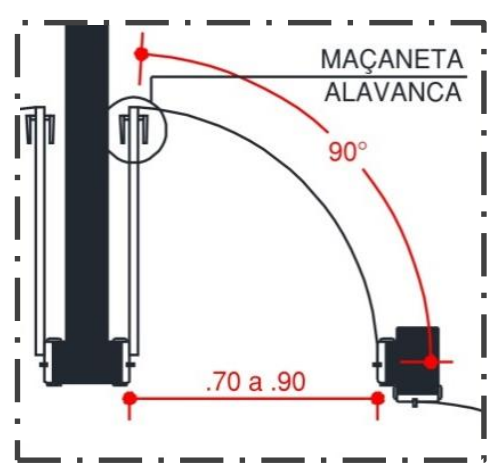

Figura 3 - Portas de correr
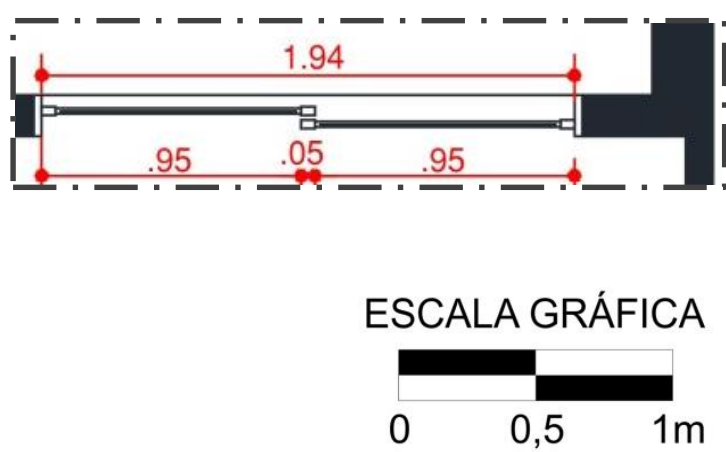

Fonte: Adaptado de Construtora R Pontes LTDA (2013)

Os vãos das portas dos quartos e dos banheiros das suítes, de $80 \mathrm{~cm}$, permitem a passagem do idoso cadeirante, mas de modo limitado, não sendo recomendada a adoção de vãos com essa largura, pois além da dificuldade que impõem ao idoso cadeirante, não satisfazem o acesso aos ambientes pelo idoso usuário dos demais aparelhos de auxílio à locomoção, visto que eles necessitam de uma largura mínima de $90 \mathrm{~cm}$ para circulação.

A porta instalada no lavabo, com apenas $70 \mathrm{~cm}$ de largura, compromete seu circuito de circulação, impossibilitando o uso desse ambiente por qualquer idoso com restrição físico-motora que utilize cadeira de rodas ou outro aparelho de auxílio ao deslocamento. Além disso, as portas de todos os banheiros não possuem abertura para fora, tornando-se um obstáculo ainda maior para esse perfil de usuário.

As portas de abrir possuem maçaneta do tipo alavanca, que facilita a utilização pelo idoso, seja ele deficiente ou não. No entanto, a altura dessas maçanetas em relação ao piso - que deve ser entre 90 e $110 \mathrm{~cm}$ - não está especificada no projeto arquitetônico disponível.

Com relação à porta da varanda, de correr, no projeto arquitetônico disponibilizado, não há indicação do local de instalação dos trilhos, devendo-se atentar para o fato de que se eles estiverem instalados na parte de baixo, devem ser nivelados com o piso e possuir largura máxima de $1,5 \mathrm{~cm}$.

\section{Circulação interna}

O corredor do apartamento possui $100 \mathrm{~cm}$ de largura livre de obstáculos, superior a mínima recomendada - de $90 \mathrm{~cm}$ - e extensão de $1,75 \mathrm{~m}$ - a máxima é de $4 \mathrm{~m}$. Assim como nos demais ambientes do apartamento, não se sabe qual o tipo de piso adotado, devido a não disponibilização do memorial descritivo do projeto.

O ideal é que todos os espaços tenham piso antiderrapante, firme, regular e estável, para não comprometer o acesso pelo idoso, seja ele deficiente ou não. Entretanto, o projeto arquitetônico não apresenta desnível na circulação interna e em nenhum dos ambientes do apartamento; ponto positivo para a acessibilidade espacial. 
Uso da unidade

\section{Orientação espacial}

Mesmo com a definição clara dos setores do apartamento, não se sabe se há uma diferenciação de tratamento entre os setores social, íntimo e de serviço, pois a construtora responsável pelo projeto não disponibilizou seu memorial.

O contraste entre os planos, gerado pela diversidade de cores, texturas e acabamentos, pode auxiliar o idoso com alguma limitação, como a cognitiva, na orientação e no mapeamento mental do apartamento, proporcionando a eles um domínio melhor do espaço doméstico. Além disso, pode tornar o uso dos ambientes por um idoso com determinado grau de deficiência visual mais fácil.

\section{Janelas}

As janelas baixas dos ambientes, com peitoril de $110 \mathrm{~cm}$, estão acima da altura recomendada, que é entre 90 e $100 \mathrm{~cm}$ em relação ao piso interno. $\mathrm{O}$ acesso às janelas baixas do apartamento é comprometido nas suítes reversíveis, visto que o espaço mínimo em frente à cama impede a circulação do idoso cadeirante ou usuário de outro aparelho de auxílio à locomoção; e na cozinha, devido ao posicionamento dos móveis e equipamentos.

Nesses ambientes as janelas não possuem vão de aproximação de no mínimo 60\% de sua largura, conforme recomendado. Com relação às janelas altas existentes nesse apartamento, destaca-se que elas não podem ser alcançadas pelo idoso cadeirante, em função de suas alturas.

Com relação aos vãos de aproximação das janelas, apenas as janelas da suíte de casal e da área de serviço possuem vão de aproximação de no mínimo 60\% de sua largura.

\section{Dispositivos e controles}

Como os projetos elétrico e hidráulico do edifício não foram disponibilizados, não é possível avaliar os interruptores, as tomadas, as campainhas, os controles de interfone e telefone, o quadro de luz, o comando de aquecedor e o registro de pressão e água do apartamento, quanto suas alturas em relação ao piso e quanto suas formas de manipulação.

\section{Setor social}

No tocante às áreas de circulação e de manobra, a sala de estar apresentou um dos melhores resultados, com seus circuitos de circulação satisfeitos e áreas de manobra de $360^{\circ}$ para a cadeira de rodas. Na sala de jantar o circuito de circulação não está plenamente satisfeito, pois a mesa de jantar prejudica o deslocamento do idoso cadeirante, ou usuário de outro aparelho de auxílio à locomoção. Além disso, o espaço para circulação entre a mesa e um dos aparadores também não é suficiente. Já a varanda e o lavado tiveram um dos piores resultados, visto que, seu circuito de circulação está insatisfeito e que ambos não possuem área de manobra suficiente para o giro de $180^{\circ}$ e de $90^{\circ}$, respectivamente.

No que diz respeito às áreas de aproximação e uso do mobiliário e dos equipamentos pelo idoso cadeirante, observa-se que na sala de estar, o acesso a todo o mobiliário - sofá, rack/estante de TV, poltrona e mesa lateral é satisfeito. Na sala de jantar, a mesa de jantar e um dos aparadores afetam a área de aproximação e uso um do outro. Já a varanda e o lavabo não possuem áreas de aproximação e uso satisfatórias em nenhum dos móveis e equipamentos que possuem. 


\section{Setor de serviço}

A cozinha possui circuito de circulação parcialmente satisfeito, prejudicado na entrada, pelo fogão. Entretanto, é possível fazer um giro de $180^{\circ} \mathrm{com}$ a cadeira de rodas no ambiente. Na área de serviço, o circuito de circulação é satisfeito, pois todo o trajeto é livre de obstáculos e o ambiente dispõe de espaço para a manobra de $90^{\circ}$.

Em relação às áreas de aproximação e uso do mobiliário e dos equipamentos pelo idoso cadeirante, na cozinha, apenas o fogão, uma das mesas de refeições e um dos móveis que funcionam como despensa têm seus acessos satisfeitos; os demais móveis e equipamentos não apresentam área de aproximação e uso necessária ao idoso cadeirante. $\mathrm{Na}$ área de serviço apenas o tanque tem a área de aproximação e uso insatisfeitos, visto que são prejudicados pela parede e porta laterais.

Na cozinha, o comprimento do balcão da pia, de $200 \mathrm{~cm}$ atende aos parâmetros recomendados, pois o mínimo necessário é $100 \mathrm{~cm}$. Dessa maneira, a pia possui vão livre inferior maior que $80 \mathrm{~cm}$ de comprimento, que é o mínimo admitido, além de apresentar área livre inferior de $77 \mathrm{~cm}$ de altura - o mínimo é $73 \mathrm{~cm}$ (Figuras 4 e 5).

Figura 4 - Comprimento do balcão da

cozinha
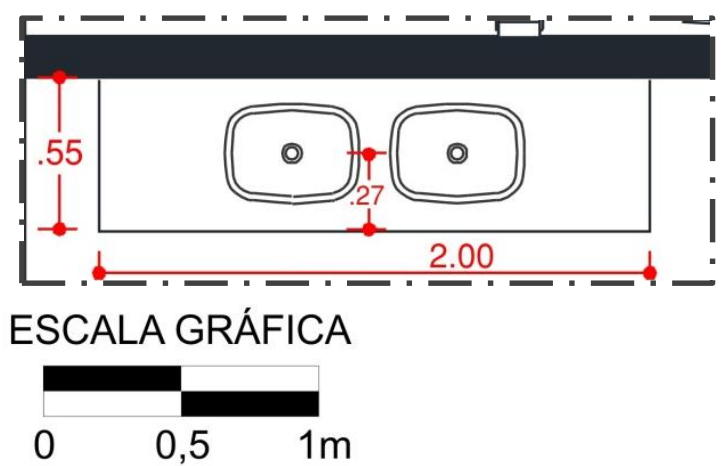

Figura 5 - Área inferior do balcão da cozinha

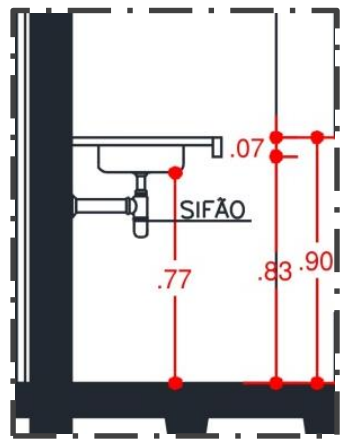

Fonte: Adaptado de Construtora R Pontes LTDA (2013)

O posicionamento do sifão e da tubulação da pia também obedece aos parâmetros estabelecidos pela norma, visto que estão situados a $27 \mathrm{~cm}$ da face externa frontal da pia - o mínimo é $25 \mathrm{~cm}$. Já a borda superior da pia, que tem altura de $90 \mathrm{~cm}$ em relação ao piso, está acima da altura máxima admitida - de $85 \mathrm{~cm}$ (Figuras 4 e 5).

Referente à área de serviço, as únicas informações existentes sobre o tanque, são a de que ele não possui área necessária e suficiente para utilização nem área adjacente de apoio. A área de serviço ainda possui área prevista para máquina de lavar adjacente ao tanque com área de aproximação e uso necessária.

\section{Setor íntimo}

Na suíte de casal, o circuito de circulação só é satisfeito ao longo da extensão do guardaroupa. Na suíte reversível 1, o dimensionamento do ambiente e o posicionamento do mobiliário impossibilitam o acesso e o deslocamento do idoso cadeirante ou usuário de outro aparelho para sua locomoção, pois não há espaço satisfatório para a realização do circuito de circulação. Na suíte reversível 2, o circuito de circulação é parcialmente 
satisfeito, pois apenas o guarda-roupa e um dos lados da cama pode ser acessado. Em nenhuma das suítes há área suficiente para a manobra de $180^{\circ}$ da cadeira de rodas.

Na maioria dos banheiros do apartamento - banheiro das suítes reversíveis - não existe área suficiente para o acesso e o deslocamento do idoso dependente de aparelho específico de auxílio à locomoção nem espaço para a manobra de $90^{\circ}$ da cadeira de rodas. Somente no banheiro da suíte de casal o circuito de circulação é parcialmente satisfeito, permitindo ao idoso com aparelho de auxílio à locomoção, o acesso aos lavatórios. No entanto, não é possível realizar um giro de $90^{\circ} \mathrm{com}$ a cadeira de rodas nesse ambiente.

No tocante às áreas de aproximação e uso do mobiliário e dos equipamentos pelo idoso cadeirante, observou-se que na suíte de casal, de todos os móveis e equipamentos existentes, apenas a mesa de cabeceira mais próxima à porta do quarto não satisfaz as condições de projeto estipuladas por Pereira para as áreas de aproximação e uso pelo idoso cadeirante. Na suíte reversível 1, apenas a parte frontal da cama tem condição de projeto satisfeita. Na suíte reversível 2, os espaços frontal e laterais da cama e o guardaroupa têm suas áreas de aproximação e uso satisfeitas; o rack da TV, a mesa de estudo e a mesa de cabeceira não possuem espaço de aproximação e uso suficientes.

O banheiro da suíte de casal possui as áreas de aproximação e uso pelo idoso cadeirante de seus lavatórios satisfeitos. As condições de projeto do vaso sanitário estão insatisfeitas, pois sua área de aproximação e uso é prejudicada pela parede lateral. O box também apresenta área de aproximação e uso insatisfeita, tendo seu acesso afetado pelo vaso sanitário. No banheiro das suítes reversíveis todos os equipamentos - lavatório, vaso sanitário e box - têm suas áreas de aproximação e uso insatisfeitas.

Os lavatórios dos banheiros possuem cuba embutida em uma bancada de granito, sem coluna central, e área adjacente de apoio, permitindo que o idoso tenha um espaço para colocar os objetos de uso cotidiano. A altura da borda superior dos lavatórios não está de acordo com as recomendações da norma, visto que está a $90 \mathrm{~cm}$ em relação ao piso - o ideal é entre 78 e $80 \mathrm{~cm}$. Entretanto, a altura da área livre abaixo da pia, de $73 \mathrm{~cm}$, obedece aos parâmetros estabelecidos - de no mínimo $73 \mathrm{~cm}$-, possibilitando a aproximação de uma cadeira de rodas ou o uso por um idoso sentado (Figura 6).

Com relação às bacias sanitárias, verifica-se, que o acento previsto em projeto possui apenas $38 \mathrm{~cm}$ de altura em relação ao piso; porém deveria estar entre $43 \mathrm{e} 46 \mathrm{~cm}$ de altura para que o idoso pudesse utilizá-lo mais confortavelmente. Considerando-se a representação gráfica da bacia sanitária no projeto arquitetônico, o dispositivo de acionamento da descarga estaria na lateral e a $72 \mathrm{~cm}$ de altura em relação ao piso, portanto, adequado, em função de seu posicionamento e da altura entre 60 e $100 \mathrm{~cm}$ (Figura 6).

Figura 6 - Lavatório e bacia sanitária dos banheiros do apartamento

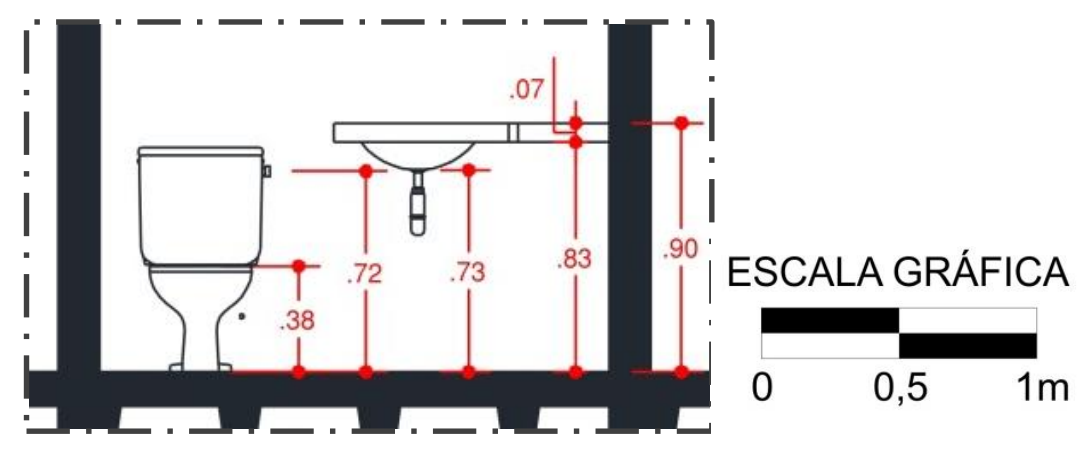

Fonte: Adaptado de Construtora R Pontes LTDA (2013) 
Apenas o box do banheiro da suíte de casal possui dimensão adequada ao acesso pelo idoso cadeirante, de 150x90cm - a mínima é 130x90cm (Figura 7). Apesar do box do banheiro das suítes reversíveis ter $1.05 \times 90 \mathrm{~cm}$ (Figura 8) - o box pode ter dimensão de $90 \times 95 \mathrm{~cm}$ com área adjacente de no mínimo $80 \times 120 \mathrm{~cm}$-, ele não possui área adjacente suficiente, que permita a transferência e a troca de roupa. Também não há, no projeto arquitetônico, indicação de desnível entre o piso do banheiro e do box.

Figura 7 - Dimensões do box do

banheiro da suíte de casal

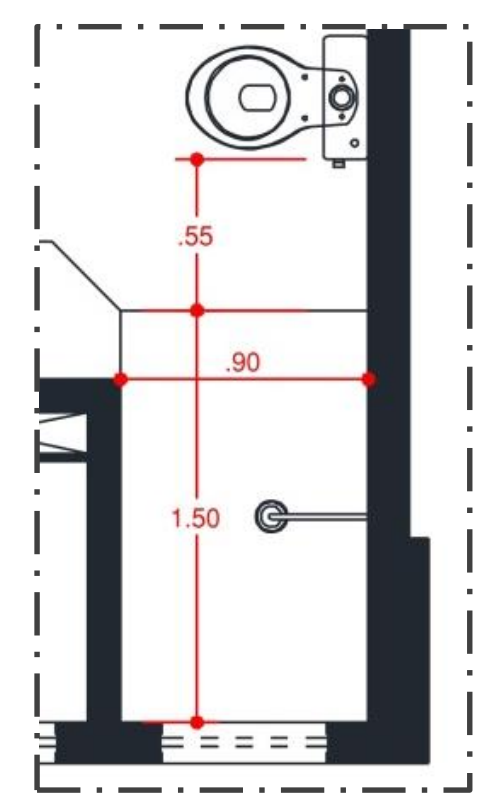

Figura 8 - Dimensões do box do

banheiro das suítes reversíveis
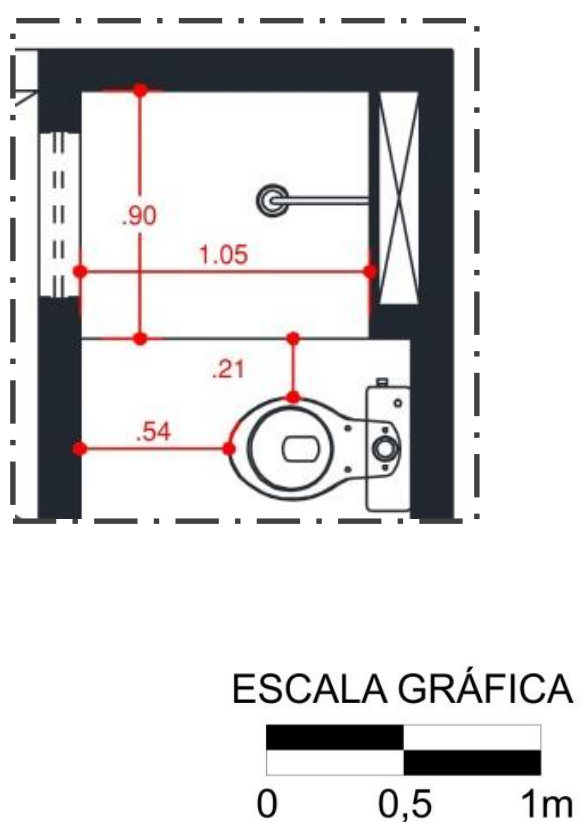

Fonte: Adaptado de Construtora R Pontes LTDA (2013)

\section{CONSIDERAÇÕES FINAIS}

Apesar de ser vendido como "o primeiro edifício adaptado para a terceira idade em Maceió", o Edifício Maison Du Versailles, apresenta sérios problemas de adequabilidade dos espaços de seus apartamentos ao idoso; os resultados obtidos comprovaram que os parâmetros de acessibilidade espacial não são plenamente atendidos.

A maioria das incompatibilidades entre os espaços e o usuário idoso evidencia que houve um subdimensionamento dos ambientes dos apartamentos em relação aos móveis e equipamentos propostos, assim como, uma má distribuição do leiaute dos ambientes, muitas vezes, ocasionada pela proposição de uma quantidade de móveis e/ou equipamentos superior ao que o ambiente poderia acomodar.

Apesar do mercado imobiliário de Maceió/AL apontar para a consciência da necessidade de se projetar moradias acessíveis ao idoso, seja em função dessa nova demanda de mercado, seja devido às exigências das leis e normas vigentes, as práticas projetuais adotadas ainda não apresentam medidas que signifiquem, de fato, alguma melhoria para a qualidade de vida de seus residentes idosos. Dessa maneira, evidencia-se que a questão da acessibilidade espacial ainda vem sendo abordada como moeda de compra e venda, buscando atrair um segmento da população em constante crescimento, os idosos, mas sem de fato se preocupar em atender suas reais necessidades. 
É responsabilidade dos profissionais da construção civil, das construtoras e do poder público criar habitações adequadas a todas as pessoas. Os problemas de acessibilidade espacial identificados nesse estudo poderiam ser evitados se os parâmetros de acessibilidade indicados nas leis e nas normas específicas vigentes fossem seguidos e se o poder público fiscalizasse a aplicação desses parâmetros nos apartamentos ofertados.

A avaliação do espaço, mesmo antes de seu uso efetivo, é fundamental para a compreensão e consequente melhoria na qualidade do projeto. Por meio dessa avaliação é possível verificar o uso potencial do ambiente por idosos, sejam eles dependentes ou não de aparelhos específicos de auxílio à locomoção. Espera-se que este trabalho, mediante novos aprofundamentos, possa servir de contribuição para que novos empreendimentos busquem atender às necessidades do idoso, possibilitando a promoção de independência e autonomia, melhorando a qualidade de vida desse usuário.

\section{REFERÊNCIAS}

ASSOCIAÇÃO BRASILEIRA DE NORMAS TÉCNICAS. NBR 9050: acessibilidade a edificações, mobiliário, espaço e equipamentos urbanos. Rio de Janeiro, 2004.

BARROS, P. (Ed.). Construtora lança em Maceió o primeiro edifício adaptado para a melhor idade. Gazeta de Alagoas, Maceió, 26 jul. 2012. Imobiliário \& Construção, caderno 2.

BESTETTI, M. L. T. Habitação para idosos. O trabalho do arquiteto, arquitetura e cidade. 2006. 181f. Tese (Doutorado em Estruturas Ambientais Urbanas). Programa de Pós-Graduação em Arquitetura e Urbanismo, Universidade de São Paulo, São Paulo.

DISCHINGER, M.; BINS ELY, V. H. M.; PIARDI, S. M. D. G. Promovendo a acessibilidade nos edifícios públicos: Programa de Acessibilidade às Pessoas com Deficiência ou Mobilidade Reduzida nas Edificações de Uso Público. Florianópolis, 2008.

DUARTE, C. R. e COHEN, R. Acessibilidade para todos: uma cartilha de orientação. Núcleo Pró-Acesso, UFRJ/FAU/PROARQ, Rio de Janeiro, 2004.

IBGE - Instituto Brasileiro de Geografia e Estatística. Perfil dos idosos responsáveis pelos domicílios. Rio de Janeiro, 2010. Disponível em: <http://www.censo2010.ibge.gov.br/ sinopse/index.php?dados=12\&uf=00> Acesso em: 14 fev. 2014.

MONTENEGRO, F. de C. Avaliação dos parâmetros de acessibilidade espacial para idosos: estudo de dois apartamentos em Maceió/AL. 2013. 143f. Dissertação (Mestrado em Arquitetura e Urbanismo). Programa de Pós-graduação em Dinâmicas do Espaço Habitado, Universidade Federal de Alagoas, Maceió.

ORNSTEIN, S. W.; ALMEIDA PRADO, A. R.; LOPES, M. E. Apresentação: trajetória da acessibilidade no Brasil. In: ORNSTEIN, S. W. (Org.); ALMEIDA PRADO, A. R. (Org.); LOPES, M. E. (Org.). Desenho universal: caminhos da acessibilidade no Brasil. 1. ed. São Paulo: Annablume, 2010. p. 9-17.

PEREIRA, G. M. Acessibilidade espacial na habitação popular: um instrumento para avaliação de projetos. 2007. 172f. Dissertação (Mestrado em Arquitetura e Urbanismo). Programa de Pós-graduação em Arquitetura e Urbanismo, Universidade Federal de Santa Catarina, Florianópolis.

ROJAS, V. B. F. Contribuição para o planejamento de ambientes construídos destinados à convivência de idosos. 2005. 147f. Dissertação (Mestrado em Engenharia). Curso de Mestrado Profissionalizante da Escola de Engenharia, Universidade Federal do Rio Grande do Sul, Porto Alegre, 2005.

R PONTES CONSTRUTORA. Edifício Maison Du Versailles. 2012. Disponível em: <http://www.rpontes.com.br/empreendimento/proximo-lancamento-maison-du-versailles/> Acesso em: 6 nov. 2012. 